\title{
Editorial \\ Rituximab treatment in rheumatoid arthritis: how does it work?
} Maria JH Boumans and Paul P Tak

Division of Clinical Immunology and Rheumatology, Academic Medical Center/University of Amsterdam, 1100 DE Amsterdam, the Netherlands

Corresponding author: Paul P Tak, p.p.tak@amc.uva.nl

Published: 24 November 2009

Arthritis Research \& Therapy 2009, 11:134 (doi:10.1186/ar2852)

This article is online at http://arthritis-research.com/content/11/6/134

(C) 2009 BioMed Central Ltd

See related research by Nakou et al., http://arthritis-research.com/content/11/4/R131

\begin{abstract}
Treatment with the chimerical monoclonal antibody rituximab results in CD20-directed $\mathrm{B}$ cell depletion. Although this depletion is almost complete in the peripheral blood of nearly all patients with rheumatoid arthritis, a proportion of patients does not exhibit a clinical response. The paper by Nakou and colleagues suggests that a decrease in CD19+CD27+ memory B cells in both peripheral blood and bone marrow precedes the clinical response to rituximab. This finding adds to the emerging evidence that lack of response to rituximab is associated with persistence of $B$ lineage cells in specific body compartments.
\end{abstract}

In a recent issue of Arthritis, Research \& Therapy, Nakou and colleagues [1] present an interesting study of the effects of rituximab treatment on $\mathrm{B}$ cell subsets in both peripheral blood and bone marrow of patients with rheumatoid arthritis (RA). In 2001, Edwards and Cambridge [2] successfully performed the first pilot trial evaluating $B$ cell depletive therapy in five patients with RA. The beneficial effect of treatment with the $B$ cell depleting chimerical antibody rituximab was confirmed in various placebo-controlled clinical trials and approval followed in 2006 in both the EU and US.

The critical role of $B$ cells in the pathogenesis of RA had previously been suggested by the association with autoantibodies (rheumatoid factor and anti-citrullinated protein antibodies), which can be found already in the preclinical phase of the disease; the presence of lymphocyte aggregates containing $B$ cells, which are often surrounded by large numbers of plasma cells, in the inflamed synovium; and experimental studies showing, for instance, the effects of immune complexes containing rheumatoid factor on tumor necrosis factor production by macrophages. The clinical benefit of rituximab treatment strongly supports the notion that $B$ cells play a key role in the pathogenesis of this disease.

What could this role be? It is known that B cells have different functions that may be relevant in the pathogenesis of
RA, which include antigen presentation, stimulation of T cells, cytokine production and production of autoantibodies. Of note, B cells are the precursors of immunoglobulin-producing plasma cells. Studies on the effects of rituximab treatment on different compartments (like peripheral blood, synovial tissue, and bone marrow) in relation to the clinical response may provide insight into the mechanism of action in RA. We and others have previously shown that rituximab causes a rapid decrease in numbers of $B$ cells in the synovial tissue of RA patients (reviewed in [3]). The early synovial tissue response varies between patients, which is in contrast to the marked $B$ cell depletion observed in the peripheral blood of nearly all patients with RA. Similar to incomplete depletion of B cells in the synovium of a subset of patients, persistent $B$ cells might be found in the bone marrow of some RA patients after rituximab treatment, although at low numbers [3]. It should be noted, however, that data on the effect on bone marrow are still limited. Persistence of B cell subpopulations at specific sites could be related to the fact that different effector mechanisms may be important for $B$ cell depletion in the different compartments. For example, experiments in a human $\mathrm{CD}^{2} \mathrm{O}^{+}$mouse showed that after treatment with an antihuman CD20 monoclonal antibody (rituximab or 2H7), complement-dependent cytotoxicity plays a dominant role in B cell depletion in the splenic marginal zone B cell compartment, whereas Fc receptor mediated mechanisms (like antibody-dependent cellular cytotoxicity) are most important in the elimination of circulating B cells as well as lymph node and splenic follicular B cells [4].

Treatment with rituximab induces an almost complete depletion of all peripheral blood $B$ cell populations in RA patients that usually lasts for 6 to 9 months. Repopulation occurs mainly by naïve $B$ cells, whereas memory $B$ cells can stay depleted for more than 2 years [5]. The same pattern of depletion and repopulation was recently shown in the bone marrow as well [6]. Of importance, the long-term reduction of

$\mathrm{RA}=$ rheumatoid arthritis. 
memory $B$ cells after rituximab treatment does not prevent the return of autoantibody production. Apparently, the autoreactive clones are not completely disrupted. Early clinical relapse has been associated with a higher proportion of CD27+ memory B cells before therapy and with a higher percentage of IgD+CD27+ memory $B$ cells or of lgD-CD27+ class-switched memory $B$ cells in the repopulating cells [7-9]. Moreover, class-switched memory B cells were found to accumulate in flaring joints [8].

Nakou and colleagues need to be commended for performing a complicated study, including bone marrow biopsies, that adds to the insight into the mechanism of rituximab therapy. Consistent with previous studies, they show that CD19+ $B$ cells in the bone marrow are only partially depleted after rituximab treatment. The local expression of $B$ cell survival factors may play a role in this phenomenon. It is also conceivable that $\mathrm{B}$ cell proliferation and plasma cell formation may continue to occur despite rituximab treatment. Future studies deciphering the mechanism underlying the persistence of B cells may help to provide a deeper understanding of why some patients do not respond to rituximab therapy. Focusing on B cell subsets, Nakou and colleagues [1] observed a decrease in CD19+CD27+ memory B cells in both peripheral blood and bone marrow 3 months after rituximab treatment in patients with a clinical response at 6 months, whereas non-responders showed an increase in CD19+CD27+ cells. It is important to realize that these changes in CD27+ B cells in peripheral blood are found in the very small proportion of CD19+ cells that could still be detected after therapy. It should also be noted that patient numbers were small and the results appear to differ from those published by Leandro and colleagues [10], who reported that $75 \%$ of the residual CD19+ cells after rituximab had a memory B cell/plasma cell precursor cell phenotype (IgD-CD27+). The data do support the hypothesis, however, that lack of response to rituximab treatment is associated with persistence of $B$ lineage cells in specific tissues, like the synovium [3] and the bone marrow [1].

\section{Competing interests}

The authors declare that they have no competing interests.

\section{References}

1. Nakou M, Katsikas G, Sidiropoulos P, Bertsias G, Papadimitraki E, Raptopoulou A, Koutala H, Papadaki HA, Kritikos H, Boumpas DT: Rituximab therapy reduces activated $B$ cells in both the peripheral blood and bone marrow of patients with rheumatoid arthritis: depletion of memory B cells correlates with clinical response. Arthritis Res Ther 2009, 11:R131.

2. Edwards JC, Cambridge G: Sustained improvement in rheumatoid arthritis following a protocol designed to deplete B lymphocytes. Rheumatology (Oxford) 2001; 40:205-211.

3. Gerlag DM, Tak PP: Novel approaches for the treatment of rheumatoid arthritis: lessons from the evaluation of synovial biomarkers in clinical trials. Best Pract Res Clin Rheumatol 2008, 22:311-323.

4. Gong $\mathrm{Q}, \mathrm{Ou} \mathrm{Q}, \mathrm{Ye} \mathrm{S}$, Lee WP, Cornelius J, Diehl L, Lin WY, Hu Z, Lu Y, Chen Y, Wu Y, Meng YG, Gribling P, Lin Z, Nguyen K, Tran $\mathrm{T}$, Zhang $\mathrm{Y}$, Rosen H, Martin F, Chan AC: Importance of cellular microenvironment and circulatory dynamics in B cell immunotherapy. J Immunol 2005, 174:817-826.

5. Roll P, Palanichamy A, Kneitz C, Dorner T, Tony HP: Regeneration of $B$ cell subsets after transient $B$ cell depletion using anti-CD20 antibodies in rheumatoid arthritis. Arthritis Rheum 2006, 54:2377-2386.

6. Rehnberg M, Amu S, Tarkowski A, Bokarewa Ml, Brisslert M: Short- and long-term effects of anti-CD20 treatment on B cell ontogeny in bone marrow of patients with rheumatoid arthritis. Arthritis Res Ther 2009; 11:R123.

7. Leandro MJ, Cambridge G, Ehrenstein MR, Edwards JC: Reconstitution of peripheral blood $B$ cells after depletion with rituximab in patients with rheumatoid arthritis. Arthritis Rheum 2006, 54:613-620.

8. Möller B, Aeberli D, Eggli S, Fuhrer M, Vajtai I, Vögelin E, Ziswiler HR, Dahinden CA, Villiger PM: Class-switched B cells display response to therapeutic $B$-cell depletion in rheumatoid arthritis. Arthritis Res Ther 2009, 11:R62.

9. Roll P, Dorner T, Tony HP: Anti-CD20 therapy in patients with rheumatoid arthritis: predictors of response and $B$ cell subset regeneration after repeated treatment. Arthritis Rheum 2008, 58:1566-1575.

10. Leandro MJ, Cooper N, Cambridge G, Ehrenstein MR, Edwards JC: Bone marrow B-lineage cells in patients with rheumatoid arthritis following rituximab therapy. Rheumatology (Oxford) 2007, 46:29-36. 